\title{
EMS Agenda
}

\section{Raymond L. Fowler, MD, FACEP}

Since the publication of the 1966 document, Accidental Death and Disability: The Neglected Disease of Modern Society, ${ }^{1}$ produced by the National Academy of Sciences/National Research Council, no single time in the history of EMS has yielded so much risk and so much opportunity.

With the stroke of a pen in 1966, the U.S. Department of Transportation and the National Highway Traffic Safety Administration were created, bringing with them mechanisms for definition of emergency medical services (EMS) personnel and (ultimately) EMS systems throughout the United States. Now, some 26 years later, the residua of the practice of EMS form a precipitate requiring careful scrutiny. Such examination forms an agenda for action.

The purpose of these few lines to elaborate upon some of the most important issues facing current EMS leaders, and to suggest a mechanism for advancement, growth, and coordination within the EMS community.

Today, the chief problem facing EMS is the absence of unity among those organizations purporting to offer aspects of EMS coordination. The list of involved organizations is extensive and beyond the scope of this paper. Rather, the substance of the division of effort is the topic.

Clubs exist within EMS essentially for every group of providers. The physicians, state directors, flight nurses, technicians, flight paramedics, pilots, state training coordinators, EMS educators, the American Society of Testing and Materials, and many others all have established organized entities around which they assemble to generate policy positions relative to their respective EMS causes. Time passes; paperwork accumulates; well-meaning but poorly aimed is sues are thrown upward into the winds of change only to settle like fine dust upon the medico-political landscape in a confused array. Real-time patient care ends up little better for the effort.

At the Executive Committee meeting of the National Association of EMS Physicians (NAEMSP) in June 1992, a Task Force was crated to begin the formation of a commonality of purpose among the various EMS representative bodies. For too long, we recognize, no common focus has provided a framework for action. It is time for this to change,

This is how the change should take place. The Task Force will invite representatives of all EMS groups willing to cooperate in establishing the top priorities among EMS systems in the U.S. These top priorities then will be ranked in terms of imminence of need for action. Individual organizations then will be encouraged to pursue action on the ranked topics.

The most vital element will come next. A clearinghouse will be developed to keep track of the actions planned, those that are in progress, and of proposals that have been realized and completed. This "library" of activity will be maintained at a location that permits convenient access, to serve as a central referral point for active EMS agencies. The EMS Agenda Action Plan will be kept in file at the clearinghouse for reference by organizations that are prepared to pursue various, creative, EMS-related activities. Completed documents and actions will be kept on file.

Why is this necessary? If the right hand does not know what the left hand is doing, little worthwhile work can be accomplished. For example, it is a waste of resources for three or four different agencies to develop guidelines for scene transfer by air ambulances. Furthermore, if these guidelines emerge in significant contrast, mixed signals are sent to providers, legislators, and health care administrators.

Other examples abound. The Basic Trauma Life Support (BTLS) versus Prehospital Trauma Life Support (PHTLS) separation is an almost ten-year-old schism that remains unbridged. Frankly, with independent incorporated entities producing each program, each with hundreds of thousands of dollars budgeted annually, it is quite unlikely that either will disappear or that merger will occur.

What is the point? How often can educators get medics away from their jobs for a couple of days for trauma education? "Not very often" is the resounding answer. Therefore, both courses should be teaching the same basic principles of how medics should examine patients. Is not hemorrhagic shock treated the same in the prehospital phase in both New Orleans and Longview? The only coordination that exists between these courses is an occasional debate, the purchase of the other's textbooks, and perhaps a phone call from time to time. Mixed signals are possible!

Recently, NAEMSP and the American College of Emergency Physicians (ACEP) could not reach agreement in the establishment of an EMS Medical Director Training Course. Hence, each has established its own program, marketed in different ways basically to the same audience. While the courses bear some resemblance to each other, shouldn't it be written somewhere that EMS systems should approach quality assurance (or quality improvement as the term is proffered these days) in the same general format?

Have you really looked to see how many different EMS trip 
sheets (ACRs, run sheets, medical records, etc.) exist in the U.S., and, sometimes, even in the same state? How many ways can the same data be recorded, and which way is best? If there is a "best" way, why can't all providers agree upon this method and utilize it?

According to Dave Samuels, reporting to the NAEMSP Annual Scientific Assembly in June 1992, ${ }^{2}$ a search was done of the EMS-ACR data of various states for the purpose of writing the new EMT-B (Basic) training curriculum. The data sets were so varied among the states that little in the way of meaningful conclusions could be drawn.

The American Society of Testing and Materials effort of the mid-1980s (and on-going) was and is laudable in its attempt to establish standards within the EMS industry. As a participant in the group for years, I have been impressed with the good intentions of the members, who provide their own funds and spend much time attempting to write EMS standards on dozens of issues. However, the geologic time frame achieved by this process seems glacial in comparison to the brisk method of achieving consensus within other organizations.

The EMS industry sorely needs a single agency wherein is logged the standards-writing efforts in progress by many U.S. organizations. Therefore, active EMS agencies must reach consensus upon a way to track individual efforts to prevent redundancy. The library of existing clinical and other standards, their dates of generation, and most recent re-write should be catalogued and made ready for reference. Most importantly, a central housing point for the EMS Agenda, an annually updated matrix, needs to be organized.

Which organizations certainly must be involved in this project?

1. The National Association of EMS Physicians;

2. The National Association of State EMS Directors;

3. The American College of Emergency Physicians;

4. The National Association of EMTs;

5. The various Air Medical Organizations;

6. The American Ambulance Association;

7. The Department of Transportation and National Highway Transportation and Safety Agency;

8. The Society for Academic Emergency Medicine;

9. The National Council of State EMS Training Coordinators; and

10. Appropriate other organizations.

This group will be the hub of the effort, and other EMS groups are encouraged to climb on board with the same rank as everyone else. Funding must be sought to bring this group together to generate the master agenda. Staff support will be required to maintain a network of contacts. Adequate and accurate recording of the work of the group and its products will be essential.

Periodic master indexes of existing documents will be generated and made available to the participating agencies. An annual update of the matrix will be conducted.

This EMS coalition can use various venues for gathering. The EMS Committee of National ACEP has attempted similar gatherings for years, and such efforts certainly are conducive to this plan. However, all efforts must be non-denominational and rapidly forthcoming to the library with the materials generated.

Finally, this EMS coalition must hoist this agenda high up on the masthead and move forward quickly. There is an uncertain future for EMS in this cost-conscious era of health care. Plugging coordinated efforts into appropriate federal agencies will have a striking impact on the future of EMS.

One such potential area for "plugging" is in the acquisition of federal funding for research. Without exaggeration, millions of federal dollars are available RIGHT NOW for research into various EMS-related projects, especially rural health care. This information must be circulated to those who need to know it. Private firms willing to support research projects should need only call a central EMS coordinating body to find out who is interested in carrying out these projects.

This idea can be played out on and on. Important issues that must be studied include liability and legal immunity, training, retraining, billing, reimbursement, equipment, clinical standards, and many, many more topics of equal concern.

Shall we do this thing, this pursuit of the EMS agenda? The NAEMSP believes that we must, and hence shall proceed with the contact of presidents of the above organizations for assistance in building this coalition and clearinghouse. Those with ideas for funding, please put them in writing and forward them to the NAEMSP at your earliest convenience.

We must look around us: Behind, beside, and ahead. Taking note of that which has gone before, continues now, and beckons from the horizon, we can enlarge this new, young, specialty of medicine for the benefit of us all.

\section{References}

1. National Academy of Sciences: Accidental Death and Disability: The Neglected Disease or Modern Society. Washington, D.C.: National Academy of Sciences/National Research Council, 1966.

2. Samuels D: Update on EMT-Basic curriculum project. Presentation to NAEMSP Scientific Assembly, June 1992, Pittsburgh, Pa. 


\section{THERE'S No Way To Treat BuRN Victims In The Field.}

\section{OR IS THERE?}

To find out how other burn specialists are treating victims in the field, call us today for the LSP distributor nearest you. 1-800-225-4577.

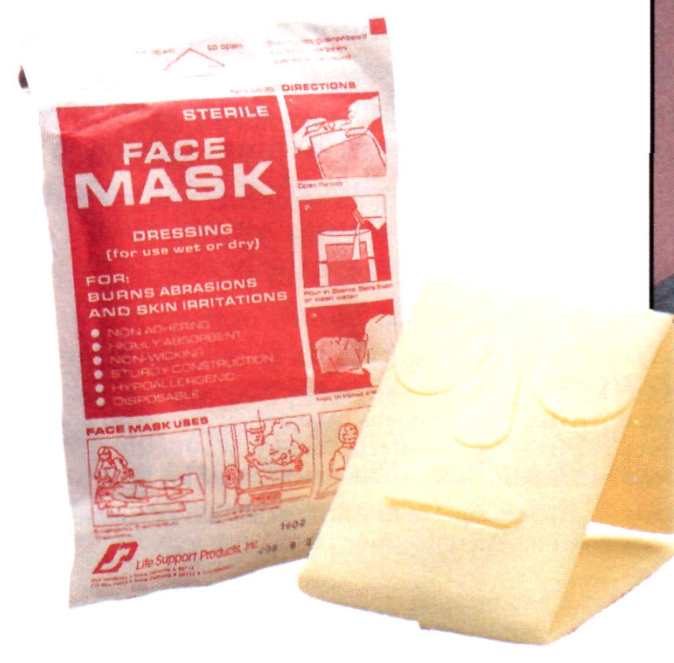




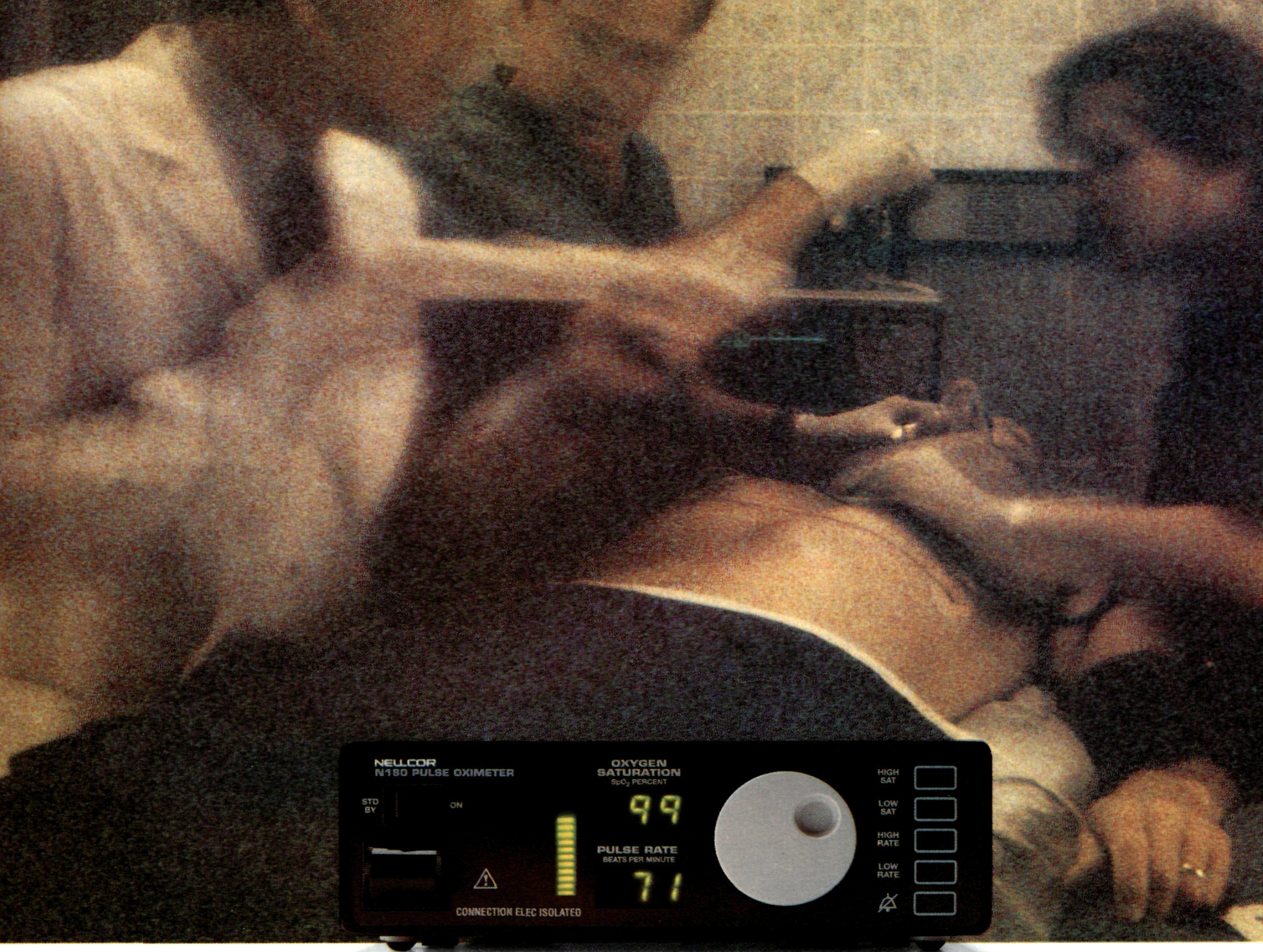

\section{There's no second-guessing when you choose us first.}

Nellcor takes patient safety seriously.

Our commitment to improving patient care and saving lives led us to introduce our first pulse oximeter for use in operating rooms in 1983. Since then, pulse oximetry has become a standard of care.

We don't take leadership lightly.

Nellcor continues to set the standard as today's market leader in pulse oximetry. The accuracy, dependability and rock-solid reliability you've come to expect from our products have been proven in virtually every clinical environment.
There's no guesswork with Nellcor's commitment to service and support, either.

We offer on-site Clinical Education Consultants who will come to your clinical environment and work with your staff. We provide comprehensive technical and clinical support. And Nellcor has the industry's most indepth inservice training. All this, plus a three-year warranty.

Don't get caught second-guessing. Choose Nellcor first.

The N-180. Nellcor does it again.

This basic, "no-frills" pulse oximeter

\section{NEULCDR}

NELLCOR is a registered trademark of Nellcor Incorporated. CNellcor Incorporated 1991 is small, lightweight and has a built-in handle for easy portability. Long, sixhour battery life, too. Plus audible alarms and large, easy-to-see visual alarms to alert you to hypoxemia problems as they occur.

For more information, contact your local Nellcor representative or call 1-800-NELLCOR, or 510-887-5858. Nellcor Incorporated, 25495 Whitesell Street, Hayward, CA 94545.

Internationally, contact European headquarters in the Netherlands at +31.73 .426565 or Asia/Pacific headquarters in Hong Kong at +852.7355618 . 


\section{Third Announcement and Call for Papers}

\section{TH WORLD CONGRESS ON EMERGENCY AND DISASTER MEDICINE}

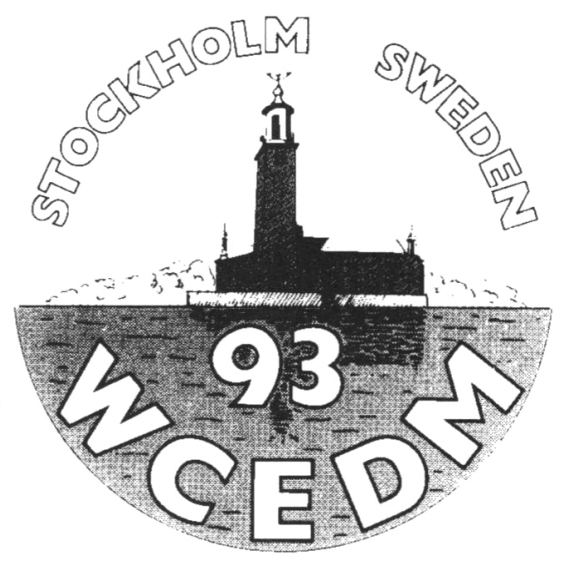

\section{0-23 JUNE 1993 - STOCKHOLM, SWEDEN}

Presented by the Swedish Society for Disaster Medicine on behalf of the World Association for Emergency and Disaster Medicine

WCEDM ' 93 will focus on disasters and emergencies related to extreme weather conditions, sea transportation, chemical and biological warfare agents, and risk assessment, particularly in connection with nuclear plants and more.

The preliminary scientific program will include state of the art lectures by internationally renowned authorities, symposia, workshops, and free paper presentations. There will be simultaneous sessions on three themes: 1) Definition and classification of disasters, disaster planning, and teaching in emergency and disaster medicine; 2) Problems related to different types of disasters; and 3) Emergency medicine, reanimatology, and traumatology.

\section{Dear Cobleague,}

We would like to exterd to you a most cordial inuitation to wisit Stockholm and attend the 8th World Congress on Emergency and Disaster Medicine in 1993.

Since the foundation of the Clab of Mainz in 1976, biennial World Congresses of Emergency and Disaster Medicine have been organized in a number of international metropoles.

The 1993 Congress is hosted by the Swedish Society of Disaster Medicine on behalf of the World Association for Emergency and Disaster Medicine. The Congress is organized in collaboration with the International Society of Disaster Medicine, the Swedish Red Crass, the Swedish National Board of Health and Welfare, and the Karolinska /nstitute.

The program will include sessions on international collaboration as well as warious aspects on Emergency and Disaster Medicine. We hope you will join us in Stockholm, the Vexice of the Nor th, in Jane 1993!

Karl-Axel Norberg

Chairman, 8th WCEDM
Borje Hallen

Secretary General, 8th WCEDM

\section{CALL FOR PRESENTATIONS - Deadline January 15, 1993}

The World Association for Emergency and Disaster Medicine is calling for presentations for the WCEDM '93. Individuals interested in submitting proposals may obtain presentation packets from:

Congress Secretariat, WCEDM '93, c/o Stockholm Convention Bureau, 